\title{
Resenha do livro "Quem aprende? Pesquisa e formação em Educação Física escolar"
}

Alex Branco Fraga*

\begin{abstract}
Resumo: Esta resenha do livro Quem aprende? Pesquisa e formação em Educação Física escolar, organizado por Vicente Molina Neto, Fabiano Bossle, Lisandra Oliveira e Silva e Mônica Urroz Sanchotene, editado pela UNIJUÍ (2009), tem por objetivo apresentar a obra e destacar as peculiaridades de cada texto.

Palavras-chave: Docentes. Educação Física escolar. Revisão.
\end{abstract}

Quem aprende? Pesquisa e formação em educação física escolar é uma coletânea de dez artigos organizada por Vicente Molina Neto, Fabiano Bossle, Lisandra Oliveira e Silva e Mônica Urroz Sanchotene, publicada pela Editora UNIJUÍ em 2009. A obra reúne, em 216 páginas, textos composto pelos "achados" em investigações de Mestrado e Doutorado do Grupo de Estudos Qualitativos Formação de Professores e Prática Pedagógica em Educação Física e Ciências do Esporte (F3PEfice), vinculado ao Programa de Pós-Graduação em Ciências do Movimento Humano (PPGCMH) da Escola da Educação Física da UFRGS.

Trata-se de uma obra academicamente relevante, teoricamente consistente e politicamente engajada, pois expõe de modo compacto um conjunto de pesquisas sobre formação de professores baseado no trabalho de campo de longa duração no interior das escolas, no diálogo constante com os colaboradores ao longo do processo e, o que é bastante singular, na discussão com colaboradores sobre as interpretações/ análises dos registros antes mesmo de serem submetidas à apreciação pública. Uma marca investigativa ou, como os próprios organizadores destacam na apresentação, um “jeitão de investigar" que remonta o início dos anos 1990, período no qual Vicente Molina Neto, coordenador do grupo, desenvolveu na Universidade de Barcelona a tese La cultura

* Doutor em Educação. Professor da Escola de Educação Física (ESEF) e do Programa de PósGraduação em Ciências do Movimento Humano (PPGCMH) da UFRGS. Porto Alegre, RS. Brasil. E-mail: brancofraga@gmail.com 
docente del profesorado de educacion fisica de las escuelas publicas de Porto Alegre.

Além disso, estudos sobre formação de professores e a prática pedagógica em Educação Física (EF), desenvolvidos em Programas de Pós-Graduação (PPG) stricto sensu não têm sido publicados sob a forma de livro com o volume esperado por quem se dedica a este campo. Muitos são os fatores que levam à redução da oferta deste tipo de publicação no Brasil, mas entre eles dois podem ser considerados bem significativos: o reduzido número de grupos de pesquisa vinculados aos PPG dedicados a esta especificidade da EF (dado apontado no primeiro capítulo da coletânea em resenha); e a sobrevalorização do formato artigo em relação ao formato livro na avaliação institucional da produção científica dos pesquisadores credenciados em PPG da área.

Na medida em que o livro tem "peso" menor na avaliação institucional de pesquisadores credenciados em PPG da área, e o credenciamento mantém um professor universitário na condição de orientador de estudantes de Mestrado e Doutorado, o simples fato de o F3P Efice investir neste formato para dar visibilidade a sua produção confere a Quem aprende um tom fortemente político. É um modo de resistir às assimetrias acadêmicas de várias ordens, um pequeno levante contra o "epistemicídio" (SANTOS, 2003) gradual da porção sociocultural e pedagógica da EF brasileira. Esta, sem dúvida, é uma das qualidades "invisíveis" desta obra.

Nas páginas de apresentação, as premissas que levaram o grupo F3P-Efice a reunir os textos sob a forma de livro ganham uma visão panorâmica, e podem ser sintetizadas no seguinte parágrafo:

\footnotetext{
Um grupo de pesquisa não se faz somente com a atividade de investigação, ele precisa também formar pesquisadores(as) e professores(as) qualificados(as), socializar o conhecimento que produz por meio de cursos e programas de formação permanente e, sobretudo, submeter as ideias que defende, o que faz e o produto de sua atividade ao exame crítico da opinião pública. Esse é o caráter desse livro e a ideia que sustenta sua organização e seu título. Quem aprende durante um processo de investigação? (MOLINA NETO et al., 2009, p. 11).
}

Movimento, Porto Alegre, v. 15, n. 04, p. 289-297, outubro/dezembro de 2009. 
É no capítulo A prática pedagógica do professorado de Educação Física no cotidiano escolar - pesquisar e aprender: metaponto de vista escrito por Vicente Molina Neto e Rosane Maria Kreusburg Molina que a especificidade das pesquisas desenvolvidas pelo F3PEfice é destacada. É um texto que funciona como marco teórico-metodológico das pesquisas realizadas pelo grupo nos últimos dez anos, e como sinalizador desta produção no mapa da produção da pós-graduação em EF no Brasil. Dá para dizer, em paráfrase ao subtítulo do capítulo, que é uma espécie de "metatexto" do conjunto da obra. Em retrospectiva, os autores examinam a trajetória do F3P-Efice, que desde 2000 centra seus estudos no cotidiano docente do professorado de EF das escolas públicas municipais de Porto Alegre. A rede municipal de ensino é o ponto de confluência de uma série de pesquisas desenvolvidas pelo grupo com o propósito de envolver o professorado de $\mathrm{EF}$ em uma relação de colaboração pautada pela noção de formação-investigação e autonomia docente. Além do locus investigativo comum, Molina Neto e Molina (2009, p. 26) destacam que a narrativa tem funcionado como alicerce metodológico sobre o qual se estabelece "uma espécie de co-autoria entre o investigador e os colaboradores" fundada em um "demorado processo de escuta". Entre os diversos estudos já desenvolvidos pelo grupo, os autores citam, a título de exemplo, uma investigação de doutorado e uma de iniciação científica que levaram a cabo uma etnografia com 16 professores de $\mathrm{EF}$ (apresentada mais detalhadamente no capítulo seguinte) e um estudo de caso com uma professora negra de EF, respectivamente.

Em ambas as pesquisas foram utilizadas observações, entrevistas e narrativas pessoais focalizadas na experiência desse coletivo docente tendo como referência o projeto político-pedagógico da rede, que organiza o currículo escolar em ciclos de formação e complexos temáticos, com ênfase na democratização da escola e no acesso ao conhecimento e também sugere o trabalho coletivo interdisciplinar, a formação dos professores e o reconhecimento à diversidade como estratégia para a operacionalização da proposta (MOLINA NETO; MOLINA, 2009, p. 26-27).

A longa experiência na coordenação de projetos de pesquisas deste tipo levou os autores a fecharem o capítulo tocando em uma dis-

Movimento, Porto Alegre, v. 15, n. 04, p. 289-297, outubro/dezembro de 2009. 
cussão extremamente instigante: o descompasso entre o tempo do gestor e o tempo do professorado. Criticam os projetos de inovação pedagógica postos em prática de maneira apressada por administradores educacionais ávidos por visibilidade midiática, mas pouco atentos às condições materiais objetivas das escolas e à cultura docente. Não há dúvidas sobre tal descompasso, até porque gestão e docência são atividades educativas de natureza distintas, o maior problema é a falta de articulação entre prática política, prática administrativa e prática pedagógica na implementação das políticas públicas. Esta falta de entrosamento entre "defesa/meio-campo/ataque" se deve em alguns casos à imposição de projetos gestados em gabinete que se pautam na adesão do professorado, e em outros, à ausência de planejamento educacional por parte do gestor de "plantão", fato que leva o professorado ao isolamento pedagógico e a saídas individualistas. Tal como apontam Molina Neto e Molina (2009, p. 32), "não é possível prescrever e controlar tudo, assim como não é possível haver completo descontrole". Por isso, os autores ressaltam a necessidade de se investir na construção de projetos de investigação, na formação de recursos humanos e na autonomia escolar como uma das formas de se manter uma rede de ensino efetivamente conectada.

As reflexões apresentadas por Molina Neto e Molina no primeiro capítulo permitem ao leitor entender a composição e o fio condutor dos nove capítulos seguintes, todos oriundos de pesquisas desenvolvidas por integrantes do F3P-Efice dentro do PPGCMH.

No capítulo A prática pedagógica da Educação Física no currículo organizado por ciclos: inovar, resistir ou abandonar? Maria Cecília Camargo Günther mostra o impacto do currículo organizado por ciclos de formação nas escolas da Rede Municipal de Ensino de Porto Alegre (RMEPA) sobre a prática pedagógica dos professores de EF. A autora situa os ciclos, que iniciam experimentalmente em 1995 e se tornam obrigatórios em 2000, dentro do projeto Escola Cidadã, implantado pela Secretaria Municipal de Educação da Administração Popular em 1994. Günther expõe sua opção pela etnografia, fundamento metodológico da sua tese de doutorado, e as justificativas teóricas para tomar a fala dos 16 professores entrevistados como narrativa. Analisa as 
inovações, permanências, resistências e transformações desencadeadas pela implantação desse sistema no cotidiano das aulas de EF a partir das impressões, entendimentos e sentimentos compartilhados entre a pesquisadora e seus colaboradores durante o processo de pesquisa.

Em O planejamento coletivo dos professores de Educação Física como possibilidade de construção da proposta políticopedagógica, Fabiano Bossle revisa a literatura e algumas concepções sobre planejamento para tentar entender a dificuldade apontada pelo professorado de EF em pôr em prática os princípios do planejamento coletivo, incorporados à proposta dos ciclos de formação da RMEPA, e assim tentar evitar que os projetos político-pedagógicos das escolas públicas fiquem a mercê de modelos de gestão empresarial dominantes no cenário educacional privado. Apesar das dificuldades encontradas para a concretização deste esforço colaborativo em uma época marcada pelo "novo gerancialismo", expressão de Michael Apple citada no texto, Bossle (2009, p. 85) entende que o planejamento coletivo em comunidades escolares pode funcionar como uma "proposta de inclusão e participação baseado em princípios de cidadania". O autor entende, fundamentado nos achados de sua pesquisa de mestrado realizada em 2003, que este modo de planejar a vida escolar levaria à "compreensão dos significados de tempo e espaço construídos na escola por toda a comunidade escolar" (2009, p. 86), e, por conseguinte, a uma melhor compreensão do "espírito" participativo imerso na organização do ensino por ciclos de formação implantados em Porto Alegre.

No capítulo Das muitas coisas que faz o professor de Educação Física na escola, Elisandro Schultz Witizorecki constrói o texto em primeira pessoa a partir da narrativa de um professor de EF da RMEPA. A experiência docente deste professor é trazida à tona através do questionamento sobre os sentidos que movem (ou emperram) o seu trabalho diário na escola. O texto foi tecido de forma compartilhada entre autor e colaborador no período em que o primeiro desenvolvia sua dissertação de mestrado no PPGCMH. Através de uma escuta aguçada e sensível, Witizorecki (2009, p. 102) não pretende, como ele mesmo afirma no texto, "capturar a realidade para interpretá-la, mas desencadear outros relatos" a partir desta primeira interpretação. Um 
tipo de produção que, mais do que dar voz ao professor (pretensão criticada por Witizorecki em uma passagem do texto em que cita Goodson), acolhe a escrita de si do colaborador em co-autoria no corpo do texto.

Em Os professores de Educação Física e interdisciplinaridade, Ricardo Reuter Pereira lida com o tema da interdisciplinaridade a partir de um estudo etnográfico realizado na RMEPA. O autor busca examinar tal tema a partir do entendimento e da prática do professorado de EF sobre interdisciplinaridade dentro dos ciclos de formação, algo também previsto nesta proposta. De modo especial, Pereira argumenta que o predomínio da prática esportiva nas aulas de EF, marcante na trajetória estudantil dos professores colaboradores, juntamente com a pouca disponibilidade destes para entender as peculiaridades das demais disciplinas escolares, é uma das tantas justificativas para as iniciativas interdisciplinares envolvendo EF serem tão tímidas na RMEPA.

Joarez Santini de certo modo introduz a temática da saúde no horizonte investigativo do F3P-Efice quando se propõe analisar no texto Fatores intervenientes no processo de desenvolvimento da Síndrome do Esgotamento Profissional em professores de Educação Física: um estudo na Prefeitura de Porto Alegre a rotina de desgaste físico e mental de boa parte dos professores da RMEPA. A partir da própria experiência de mais de 25 anos como professor da rede, Santini (2009, p. 121) mostra como "o sofrimento e o desencanto com a tarefa docente e uma relação difícil com a comunidade escolar, além de um descomprometimento pessoal com o trabalho" vão esgotando as energias do professorado. Discorre sobre a síndrome em si e sobre como as escolhas profissionais, a formação acadêmica, as condições de trabalho, os fatores sociais e as relações interpessoais concorrem para o agravamento do quadro individual de professores acometidos por tal enfermidade. Santini demonstra de modo muito contundente, e bem sustentado, que as explicações centradas em causas únicas geram distorções na análise do fenômeno e fazem proliferar medidas paliativas para um problema tão complexo.

Produção de conhecimento (e de aprendizagem) entre sujeitos: o desafio da pesquisa, escrito por Lisandra Oliveira e Silva, é um capítulo essencialmente metodológico. A autora trata de explicitar o 
modus operandi da observação participante, que lhe permitiu compreender o processo de identização docente de cinco professoras de EF da RMEPA em sua pesquisa de mestrado. Silva reflete sobre os efeitos da observação participante no pesquisador a partir de uma situação bastante inusitada e muito rica para a compreensão dos bastidores de uma pesquisa deste tipo. A pesquisadora mostra como pode ser inquietante para o observador participante se ver na posição de observado pelo seu colaborador, especialmente quando o colaborador faz questão de se declarar em tal posição, como ocorreu com Silva (2009, p. 144) em um dado momento do trabalho de campo, quando a colaboradora lhe disse o seguinte: "por que você cruzou os braços agora? Eu também estou te observando". A partir daí, discorre de forma detalhada sobre os procedimentos a serem adotados e as inversões requeridas para quem pretende enveredar pelo campo das pesquisas qualitativas em contato direto com comunidades escolares.

No capítulo $O$ que fazem os professores nas escolas: sob uma Educação Física de mesmo formato estão "em jogo" diferentes socializações, Mônica Urroz Sanchotene aborda a temática do esporte na constituição das práticas pedagógicas dos professores de EF da RMEPA sob uma perspectiva muito interessante e criativa. Ela percebe que diante da aparente mesmice da paisagem esportiva das aulas de EF, “"escondem-se' práticas, objetivos e socializações muitos diversas" (2009, p. 157). Tal "sacada" adveio de um estudo de caso de caráter etnográfico, desenvolvido por mais de um ano em uma escola da RMEPA, no período em que fazia sua dissertação de mestrado, e apresentado de maneira sucinta no texto. $\mathrm{O}$ argumento central ganha solidez empírica quando a autora mostra de maneira detalhada as nuances da prática, do entendimento e das intencionalidades dos professores em relação a este clássico conteúdo escolar da EF.

Marzo Vargas dos Santos, em A percepção de estudantes negros sobre relações étnico-raciais e práticas corporais: considerações iniciais a partir de um grupo de discussão, analisa os discursos sobre diferenças étnico-raciais a partir dos significados atribuídos pelos estudantes negros (maioria nas periferias onde se localizam as escolas da RMEPA) às situações de racismo, veladas ou escancaradas, que vivenciam nas escolas de um modo geral e nas

Movimento, Porto Alegre, v. 15, n. 04, p. 289-297, outubro/dezembro de 2009. 
aulas de EF em particular. Para tanto, Marzo (2009, p. 185) se vale da materialidade da fala extraída de um grupo de discussão formado exclusivamente por estudantes negros, que tinha por objetivo "diminuir a possibilidade de que alguma situação de discriminação ou constrangimento inviabilizasse o debate" e contaminasse os achados da sua pesquisa de mestrado. $\mathrm{O}$ autor aponta que os estudantes negros reunidos neste encontro veem a EF, apesar de estar muito longe de ser uma zona livre de racismo, como um espaço possível de afirmação da negritude, especialmente pela identificação positiva com atletas negros bem sucedidos, mas não deixam de expor o preconceito racial socialmente camuflado neste e noutros espaços da escola, bem como não deixam de reivindicar urgência na efetivação de políticas afirmativas.

Investigação e docência: contribuições e fronteiras do caminho percorrido entre esses dois lugares, escrito por Vera Regina Oliveira Diehl, é o capítulo que fecha a coletânea. Apesar de não ter sido explicitado o critério de ordenação dos textos, este talvez tenha sido ali alocado porque tematiza a experiência professor-pesquisador de modo mais explícito. Diehl enfatiza em sua análise a simultaneidade das experiências de docente ingressante na RMEPA e ao mesmo tempo de pesquisadora iniciante do PPGCMH. Situação que permitiu a autora construir algumas saídas bem criativas como o "diário da docência", uma forma de registro de suas vivências do cotidiano docente que lhe deu mais segurança para desencadear diálogos sobre as práticas pedagógicas junto aos colaboradores. Ela enfatiza que nestes casos é preciso saber lidar com os conhecimentos prévios e exercitar o estranhamento daquilo que se apresenta como familiar nesta posição "híbrida" dentro de uma mesma rede de relacionamentos. Diehl observa que assim como o exercício docente afetou de modo positivo o seu desempenho como pesquisadora, a sua presença como pesquisadora também afetou positivamente a prática docente dos colaboradores, ou seja, gerou aprendizagens compartilhadas. E me parece que é justamente aí, nessa afetação recíproca entre os diferentes sujeitos desta rede de pesquisa, que uma resposta a pergunta título do conjunto da obra pode ser esboçada: aprende quem souber ler Quem aprende?

Movimento, Porto Alegre, v. 15, n. 04, p. 289-297, outubro/dezembro de 2009. 


Summary of the book "Quem aprende? Pesqui-
sa e formação em Educação Física escolar"
Abstract: This summary of the book Quem aprende?
Pesquisa e formação em educação física escolar (Who
Learns? The Formation Research in Physical Education
at School), organized by Vicente Molina Neto, Fabiano
Bossle, Lisandra Oliveira e Silva e Mônica Urroz Sancho-
tene, edited by UNIJUí (2009), has the objective of presen-
ting the book and highlighting peculiarities of each text.
Keywords: Faculty. Physical Education. Review.

Reseña del libro "Quem aprende? Pesquisa e formação em Educação Física escolar"

Resúmen: Esta reseña del libro Quem aprende? Pesquisa e formação em educação física escolar, organizado por Vicente Molina Neto, Fabiano Bossle, Lisandra Oliveira e Silva e Mônica Urroz Sanchotene, editado por la UNIJUÍ (2009), tiene por objetivo presentar el libro y destacar las peculiaridades de cada texto.

Palabras clave: Docentes. Educación Física. Revisión.

\section{REFERÊNCIAS}

MOLINANETO, Vicente; BOSSLE, Fabiano; SILVA, Lisandra; SANCHOTENE, Mônica (Org.). Quem aprende? Pesquisa e formação em educação física escolar. ljuí; UNIJUÍ, 2009.

SANTOS, Boaventura de Sousa. Pela mão de Alice: o social e o político na pósmodernidade. 9. ed. São Paulo: Cortez, 2003. 